\title{
Interpretation of single progesterone measurement in diagnosis of anovulation and defective luteal phase: observations on analysis of the normal range
}

\author{
N C WATHEN, L PERRY, R J LILFORD, T CHARD
}

\begin{abstract}
Single serum progesterone determinations were made in 79 apparently normal women with a regular menstrual cycle. A normal range (40 subjects) was derived from the concentrations in the follicular phase and used to define an "anovular" range for luteal phase values (nine out of 39 subjects). The remaining luteal phase values were used to construct an "ovular" range for the luteal phase and, within this range, to define a group of values. (less than the 20th centile) which could be described as a "defective luteal phase." The cut off limits between ovular and anovular and between normal and defective luteal phases were respectively two and four times the follicular phase median.

It is proposed that the numerical findings of this study may be used as a rule of thumb for defining normality and abnormality from a single serum progesterone determination.
\end{abstract}

\section{Introduction}

The term "defective luteal phase" is used to describe the condition in which infertility is a result of inadequate secretion of progesterone by the corpus luteum. ${ }^{1-4}$ The amount of progesterone secreted is insufficient to maintain the appropriate milieu for the implantation of the blastocyst and early develop-

Departments of Reproductive Physiology and Obstetrics and Gynaecology, St Bartholomew's Hospital Medical College and The London Hospital Medical College, London

N C WATHEN, MRCOG, senior lecturer

L PERRY, BSC, biochemist

R J LILFORD, MRCP, MRCOG, lecturer

T CHARD, MD, FRCOG, professor of reproductive physiology

Correspondence to: Professor T Chard, Medical College, St Bartholomew's Hospital, London EC1A 7BE. ment of the embryo. The diagnosis has been made by several means, including timed endometrial biopsy, basal body temperature, vaginal cytological studies, and ultrasound. In recent years, with the ready availability of progesterone determinations by radioimmunoassay, increasing use has been made of serum progesterone estimations in the second half of the cycle. Typically the results of such estimations are analysed in relation to an arbitrary cut off limit-for example, $16 \mathrm{nmol} / \mathrm{l} ; 5 \mathrm{ng} / \mathrm{ml}^{5-9}$ Results above this are described as normal, while those below it constitute the diagnosis of defective luteal phase and the patient is managed as such.

The definition of "abnormal," however, implies a knowledge of the normal, and the latter should (but often does not) take account of the fact that many apparently "normal" cycles are anovular. ${ }^{10}$ On the basis of an arbitrary cut off point these will be included in the diagnosis of defective luteal phase even though the clinical and therapeutic implications are obviously distinct. In principle the presence or absence of ovulation may be ascertained by other means-most notably, detection of a peak of luteinising hormone; this information is available in most research studies. In real life practice, however, such evidence is the exception rather than the rule. Indeed, the serum progesterone concentration in the second half of the cycle is itself very often the only index of whether or not ovulation has occurred. In addition, the use of a fixed cut off point-usually derived from published reports-pays no recognition to the well known fact that different radioimmunoassays for progesterone may give widely different results. Thus different assays may specify quite different populations of normal and abnormal.

In this study we examine single progesterone concentrations in a normal population of women of reproductive age; "normal" in this case refers to the fact that the subjects had no specific complaints relevant to menstruation or fertility. We analyse the findings with the aim of deciding limits for the diagnosis of anovulation on the one hand and of normal and abnormal luteal function on the other. Finally, we suggest a method by which the results of these and other similar investigations may be used to define limits for any given progesterone radioimmunoassay. 


\section{Subjects and methods}

Single blood samples were collected from 40 normal women in the follicular phase of the menstrual cycle (day 0 to day 12) and from 39 women in the mid-luteal phase (day 0 minus 10 to day 0 minus 4 with respect to the next menstrual period). Ages ranged from 18 to 42 years. None of the subjects had any complaint relevant to menstruation or fertility, and in each case there was a history of regular menstruation (range 26-35 days) for six cycles preceding the sample cycle. The date of onset of the last menstrual period was known accurately and none of the subjects was using a hormone preparation.

Serum samples were stored at $-20^{\circ} \mathrm{C}$ until assayed. Serum progesterone was measured by a direct radioimmunoassay carried out at pH 4 to obviate the need for extraction. Standard or sample was mixed with a tracer of $11 \alpha-O H$-progesterone-glucuronyl-126Iiodotyramine and an antiserum to $11 \alpha-\mathrm{OH}$-progesterone-glucuronylbovine serum albumin raised in a goat. After incubation for two and a half hours separation was achieved by adding $20 \%$ polyethylene glycol. The cross reaction of this system was $<1 \%$ for a wide range of steroids with the exception of $11 \alpha-\mathrm{OH}$-progesterone and $11 \beta-\mathrm{OH}-$ progesterone, which had potencies of $84 \%$ and $49 \%$ respectively.

\section{Results}

Table I and the figure show the serum progesterone concentrations in the follicular phase of the menstrual cycle. The 90 th centile of these values was chosen as the cut off point for interpretation of values in the mid-luteal phase-that is, concentrations of $9.8 \mathrm{nmol} / 1$ $(3.1 \mathrm{ng} / \mathrm{ml})$ or less, being identical with values in the follicular phase, were taken as presumptive evidence of anovulation. Table II and the figure show the serum progesterone concentrations in the mid-luteal phase after exclusion of the nine subjects who could be considered as anovular on the above criterion. From the data in the figure an arbitrary cut off point at the 20 th centile $(20.5 \mathrm{nmol} / 1 ; 6.5 \mathrm{ng} / \mathrm{ml})$ was proposed. This then defined a zone in which it was possible with reasonable confidence to state that ovulation had occurred but in which the values were low relative to the whole group of ovulatory subjects.

Table III gives the median value in the follicular phase and other statistical limits expressed as a multiple of this median. After rounding

TABLE I-Range of serum progesterone concentrations in follicular phase of menstrual cycle

\begin{tabular}{lllcl}
\hline Centile & 10th & 50th (median) & $\begin{array}{c}90 \text { th } \\
\text { Progesterone (nmoi/i) }\end{array}$ \\
& $\cdots$ & 3.0 & 5.5 & 9.8 \\
\hline
\end{tabular}

Conversion: SI to traditional units-Progesterone: $1 \mathrm{nmol} / 1 \approx 0.3 \mathrm{ng} / \mathrm{ml}$.

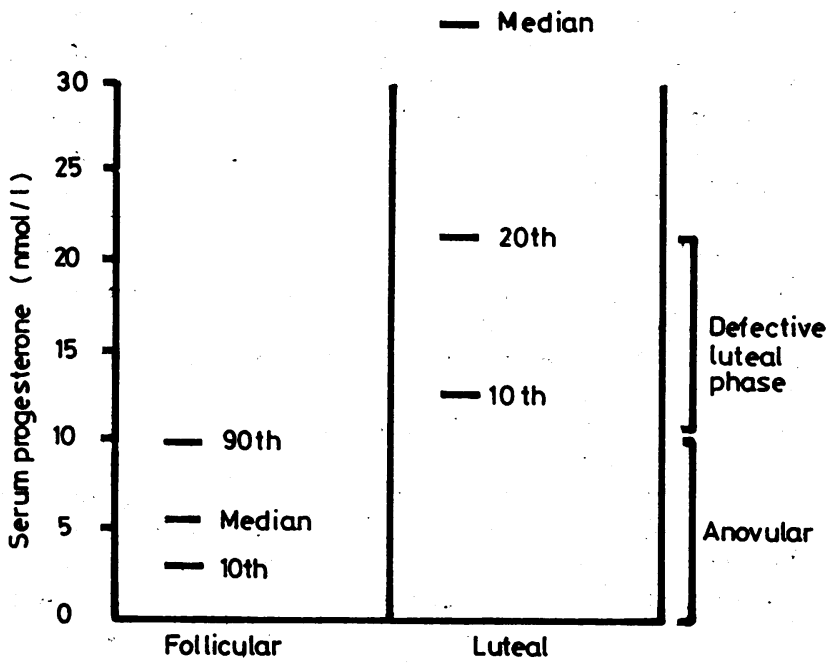

Range of serum progesterone concentrations in $\mathbf{4 0}$ women in follicular phase of menstrual cycle and in 30 women with an "ovular" luteal phase. Ranges proposed for diagnosis of an anovular cycle and of defective luteal phase also shown.

Conversion: SI to traditional units-Progesterone: $1 \mathrm{nmol} / 1 \approx 0.3 \mathrm{ng} / \mathrm{ml}$.
TABLE II-Range of serum progesterone concentrations in mid-luteal phase (day 0 minus day 10 to 0 minus 4 with respect to next menstrual period) in all subjects with values above 90th centile of follicular phase range-that is, in subjects with presumptive evidence of ovulation

\begin{tabular}{|c|c|c|c|c|c|}
\hline $\begin{array}{l}\text { Centile } \\
\text { Progesterone (nmoili)* }\end{array}$ & $\because$ & $\begin{array}{c}10 \text { th } \\
12 \cdot 5\end{array}$ & $\begin{array}{l}20 \text { th } \\
20 \cdot 5\end{array}$ & $\begin{array}{c}50 \text { th (median) } \\
32 \cdot 7\end{array}$ & $\begin{array}{l}90 \text { th } \\
51 \cdot 3\end{array}$ \\
\hline
\end{tabular}

*Progesterone: $1 \mathrm{nmol} / 1 \approx 0.3 \mathrm{ng} / \mathrm{ml}$.

TABLE III-Ranges of serum progesterone concentrations during menstrual cycle expressed as multiple of median in follicular phase. (For convenience key cut off points may be rounded up to 2 and 4 )

\begin{tabular}{|c|c|c|c|}
\hline & & $\underset{(\mathrm{nmol} / \mathbf{l})^{*}}{\text { Value }}$ & $\begin{array}{c}\text { Multiple of } \\
\text { median }\end{array}$ \\
\hline $\begin{array}{l}\text { Follicular phase median } \\
\text { 90th centile of follicular phase } \quad . . \\
\text { "Ovular" luteal phase median } \\
\text { 20th centile of "ovular" luteal phase }\end{array}$ & $\begin{array}{l}\cdots \\
\because \\
\cdots\end{array}$ & $\begin{array}{r}5 \cdot 5 \\
9 \cdot 8 \\
32 \cdot 8 \\
20 \cdot 5\end{array}$ & $\begin{array}{l}1 \cdot 0 \\
1 \cdot 8 \\
6 \cdot 0 \\
3 \cdot 7\end{array}$ \\
\hline
\end{tabular}

*Progesterone: $1 \mathrm{nmol} / 1 \approx 0.3 \mathrm{ng} / \mathrm{ml}$.

these multiples to the nearest integer we propose the following simple scheme for describing clinical cut off points of serum progesterone concentrations in the mid-luteal phase: that values less than twice the follicular median constitute presumptive evidence of anovulation, and that values between two and four times the follicular median are evidence for a defective luteal phase.

\section{Discussion}

These findings reflect on several biological, clinical, and diagnostic aspects of the use of serum progesterone determinations. We emphasise that the studies focused on single determinations, not because these are the most efficient index of ovulatory function (serial values are of much greater value) but because the realities of clinical practice dictate that a single value is much the commonest parameter for which interpretation is sought.

The first and rather obvious assumption made in this study was that progesterone concentrations in the follicular phase reflect ovarian function in the absence of the corpus luteum. If values lie within this range in the luteal phase it is impossible to say that ovulation has occurred unless there is ancillary evidence to that effect. On this basis the incidence of anovulation in our study group was relatively high (nine of 39 subjects; $23 \%$ ), given that the subjects were selected for their apparent normality. There is, however, no reason to suppose that the presence or absence of ovulation would particularly affect the follicular phase values of progesterone, and thus the overall interpretation of the findings should not be influenced by this bias.

If there is specific evidence of ovulation such as a mid-cycle peak of luteinising hormone then it is possible to define all relatively low values of progesterone as being the result of a "defective corpus luteum." Such evidence, however, is remarkably uncommon in routine clinical practice and very often a decision is sought solely on the basis of one measurement of progesterone without supporting data. Under these circumstances we propose the following: (a) that all values in the follicular phase range should be treated as anovular; and (b) that a zone of values above this range, but which are still relatively low, should be selected as suggesting defective luteal function. We therefore propose an arbitrary limit at or close to the 20th centile of the ovular range $(20 \mathrm{nmol} / 1 ; 6.3 \mathrm{ng} / \mathrm{ml})$ (figure); the range between this and the upper limit of the follicular range constitutes the diagnosis of defective luteal phase.

We accept that these definitions are arbitrary and scientifically unsatisfactory. The study does not even show that there is anything abnormal (in terms of fertility) about the so called "abnormal" ranges, nor does it take into account variation 
between successive cycles in the same subject. Nevertheless, with occasional exceptions ${ }^{4}{ }^{911-13}$ there are very few published data which can be described as greatly superior. We do not seek to present arguments for or against the existence of the accepted clinical concepts. We are not aware of any previous attempts to define ranges in this manner, even though several cut off points have been described, ranging from $9.6 \mathrm{nmol} / 1$ $(3.0 \mathrm{ng} / \mathrm{ml})^{14}$ to $38 \mathrm{nmol} / 1(12.0 \mathrm{ng} / \mathrm{ml}) .^{13} \mathrm{In}$ addition, it is worth while re-emphasising that the principles of management of anovulation and defective luteal phase are quite different. There is well accepted and effective treatment for anovulation but little or no controlled evidence that current treatment of luteal phase deficiency is of any value. Thus it is of obvious therapeutic importance to distinguish the two conditions.

Another important feature of this study is the definition of the clinical cut off points as multiples of the follicular phase median. The purpose of this is as follows. It is well known that different assay systems (especially radioimmunoassay systems using different sets of reagents) give different numerical results. Thus an individual laboratory cannot rely entirely on published normal ranges or definitions of abnormality. Equally, the smaller unit cannot do its own clinical trial to define these ranges; even the quite simple investigation described here required appreciable time and effort. It should, however, be possible for any unit to collect a small group (10-20) of samples from apparently normal subjects in the follicular phase-a process aided by the fact that values are stable over this period and exact timing is not important. A median may be derived from this set of values and the multiples of the median then used to extrapolate an upper limit for the follicular phase or "anovular" values and a range for defective luteal function. For convenience, the limits so defined may be rounded to the nearest whole number. In this way the small unit can calculate with reasonable confidence a set of clinical action lines which would otherwise require a lengthy and tedious clinical study.

\section{References}

1 Moszowski E, Woodruff JD, Jones GS. The inadequate luteal phase. Am $\mathcal{F}$ Obstet Gynecol 1962;363:162-83.

2 Jones GS. Luteal phase insufficiency. Clin Obstet Gynaecol 1973;16: 255-72.

3 Jones GS. The luteal phase defect. Fertil Steril 1976;27:351.

4 Lenton EA, Cooke ID. Investigation and assessment of the infertile woman by comparison with the endocrine parameters of a fertile cycle. INSERM $1981 ; 103: 387-408$.

${ }^{5}$ Ross GT, Cargille CM, Lipsett MB, et al. Pituitary and gonadal hormones in women during spontaneous and induced ovulatory cycles. Recent Prog Horm Res 1970;26:1-62.

6 Abraham GE, Odell WD, Swerdloff RS, Hopper K. Simultaneous radioimmunoassay of plasma FSH, LH, progesterone, 17-hydroxyprogesterone and estradiol-17 during the menstrual cycle. $\mathrm{f}$ Clin Endocrinol Metab 1972;34:312-8.

'Abraham GE, Maroulis GB, Marshall JR. Evaluation of ovulation and corpus luteum function using measurements of plasma progesterone. Obstet Gynecol 1974;44:522-5.

${ }^{8}$ Shaaban MM, Klopper A. Plasma oestradiol and progesterone concentration in the normal menstrual cycle. Fournal of Obstetrics and Gynaecology of the British Commonwealth 1973;80:776-82.

- Schmidt-Gollwitzer M, Eiletz J, Sackmann U, Nevinny-Stickel J. Detection of ovulation by a radioreceptor assay for human luteinising hormone. F Clin Endocrinol Metab 1978;46:902-6.

10 Coutts JRT, Adam AH, Flemming $R$. The deficient luteal phase may represent an anovulatory cycle. Clin Endocrinol Metab 1982;17:389-94.

11 Tulchinsky D, Hobel CJ. Plasma human chorionic gonadotrophin, estrone, estradiol, estriol, progesterone and 17-hydroxy progesterone in human pregnancy. III. Early normal pregnancy. Am f Obstet Gynecol 1973;117:884-93.

12 Hull MGR, Savage PE, Bromham DR, Ismail AAA, Morris AF. The value of a single progesterone measurement in the mid-luteal phase as a criterion of a potentially fertile cycle ("ovulation") derived from treated and untreated conception cycles. Fertil Steril 1982;37:355-60.

13 Abdulla U, Diver MJ, Hipkin LJ, Davis JC. Plasma progesterone levels as an index of ovulation. Brf Obstet Gynaecol 1983;90:543-8.

14 Israel R, Mishell DR, Stone SC, Thornycroft IH, Ayer DL. Single luteal phase serum progesterone assay as an indicator of ovulation. Am F Obstet Gynecol 1972;112:1043-6.

(Accepted 25 October 1983)

\begin{abstract}
Concentrations of vasoactive intestinal polypeptide were measured in blood drawn from the cavernous spaces of corpus cavernosum of the human penis during tumescence and erection, and the effect of injecting the polypeptide into the cavernous spaces was studied. A significant release of the polypeptide was shown during
\end{abstract}

Institute of Medical Physiology B, Panum Institute, University of Copenhagen, DK-2200 Copenhagen N, Denmark

BENT OTTESEN, MD, research fellow

GORM WAGNER, $M D$, associate professor

Centre d'Etudes et de Recherches de l'Impuissance, Paris, France RONALD VIRAG, MD, chairman

Department of Clinical Chemistry, Bispebjerg Hospital, University of Copenhagen, Denmark

JAN FAHRENKRUG, $M D$, chairman

Correspondence and reprint requests to: Dr Bent Ottesen. tumescence and erection. Injection of exogenous vasoactive intestinal polypeptide induced erection.

These findings support the concept of vasoactive intestinal polypeptide as a neurotransmitter in penile erection and suggest that it might have a clinical use in patients suffering from erectile dysfunction.

\section{Introduction}

The 28 amino acid peptide vasoactive intestinal polypeptide has been found in nerve fibres throughout the body. ${ }^{1}$ Evidence has been put forward that it functions as a neurotransmitter in several non-adrenergic, non-cholinergic physiological events. ${ }^{12}$ An essential part of the mechanism leading to penile erection is non-adrenergic, non-cholinergic relaxation of vascular and cavernous smooth muscle. ${ }^{3-6}$ The recent finding in the male genital tract of nerves containing vasoactive intestinal polypeptide that seemed to innervate blood vessels, ${ }^{7-9}$ and the relaxant effect of the polypeptide on cavernous smooth muscle, suggest that it may act as a neurotransmitter in penile erection.

In the present study we investigated the local release of vasoactive intestinal polypeptide during erection and the effect of administering the polypeptide direct into the cavernous body. 